\title{
Platform Evolution: A Study of TripAdvisor
}

\author{
Cristina Alaimo \\ Surrey Business School, UK \\ c.alaimo@surrey.ac.uk
}

\author{
Jannis Kallinikos \\ London School of Economics, UK \\ j.kallinikos@1se.ac.uk
}

\author{
Erika Valderrama-Venegas \\ London School of Economics, UK \\ e.a.valderrama-venegas@1se.ac.uk
}

\begin{abstract}
The recent commercial expansion of social media platforms challenges their origin as places of networking and community building and raises important questions as regards their status as institutional entities. After briefly reviewing the literature on platforms and ecosystems, we conduct a longitudinal case study of TripAdvisor. Our findings show the critical role networking and social data have historically played in positioning TripAdvisor as a hub in a vast digital travel ecosystem. At the same time, our analysis unravels the growing diversification of data types linked to the roles performed by different types of actors (e.g. end users, advertisers, business owners, online travel agencies). The shifting nature of these roles and the data types they produce largely account for the patterns of platform evolution and its market position.
\end{abstract}

\section{Introduction}

Over the last twenty years, social media platforms have rapidly evolved as organizations and business actors. Starting as websites facilitating connectivity among users, social media sites have grown to large and differentiated business ecosystems. Many of these sites have become massive data production farms that extract value from the data footprint of the activities users perform online, e.g. liking, rating, tagging or following, [2] [14], which they commonly monetize by revenues from advertisement.

The recent development of commercial services that rely on data other than those produced by user involvement (e.g. the much-anticipated creation of Facebook's own digital currency or the real-time personalized booking services of TripAdvisor), introduce new elements into the operations of social media that reconfigure the role of users and redefine the position of social media platforms in the digital economy. Far from being trivial, these changes raise important questions concerning the distinct status of social media as business actors and the degree to which their operations continue to be dependent on the activities of users as content and data generators. Social media are different from commercial platforms (i.e. Amazon, eBay) because they base their operations on data other than transactional derived from different forms of sociality and user engagement (i.e. reading, listening to music, travelling, connecting with friends, dating, etc.) [23]. What role would such data play in the current proliferation of social media services of more traditional type? What kind of ecosystems emerge as social media diversify their operations? To address these questions, we find important to place the study of social media in a broader purview that charts their evolution over time [10]. We draw on a longitudinal case study of TripAdvisor that retraces the evolution of the platform and identifies the transformations it has undergone over time. We contribute to the literature on digital platform evolution by using the case as the basis for theorizing on the role of data types and user types in shaping the patterns of social media evolution and their current transformation to diversified service ecosystems [47].

The paper is structured as follows. In the next section we briefly review the literature on social media and outline a few issues that require further attention and research. We subsequently present our case study of TripAdvisor. After a section on research methodology, we move on to reconstructing at some length the evolution of TripAdvisor from a travel search engine to a central actor of the global travel and hospitality industry. Following it, we analyze our empirical case and discuss the production of different data types which we view as the key elements that drive the evolution of the platform into a service ecosystem. We conclude by outlining our findings and research contribution to the wider literature on digital platforms and ecosystems.

\section{Literature Review and Positioning}

The literature on social media is large, fragmented and cross-disciplinary (see e.g. [8]) and, for these reasons, hard to overview and summarize. Mostly in line with what was their early identity, the literature origi- 
nally conceived of social media as social networking sites and studied them, accordingly, as online facilities through which people link and interact with one another (e.g. [7] [27]). This strand of literature considered the networking or community element as the defining attribute of early social media sites and the basis for singling them out as a particular type of social and economic entities [5]. The presence of large populations of users and the shifting networks that emerged as users created and shared content online were seen as the distinct mark of social media organizations [26].

However, the evolution of the Internet, the development of data handling technologies and the quick adoption of mobile devices brought about the deep economic involvement of social media and put their conception as sites of community and networking under a hard test. A great deal of social media has over time grown to complex and operationally diversified business actors. It is obvious that the current economic position of social media cannot straightforwardly be deduced from their networking attributes.

Seeking to address the organizational, technological and economic complexity of social media and the links social media companies maintain to the growing digital economy an alternative conception of social media as platforms has gained currency over the recent years (see e.g. [2] [3] [12] [14] [20]). As distinct from the notion of networking sites, the concept of platform redirects attention beyond the activities of online communities and groups to the organizational configurations, technological infrastructures and business processes of social media and their embedment in larger business ecosystems [13]. Platforms are not just networking sites.

This strand of literature draws upon and partly coincides with the conception of digital platforms as twosided or multisided markets, in which different types of participants trade their interests under a set of rules and conditions that are shaped by the nature of each platform (type of product or service traded) and the ways it is governed (platform owners). Social media fit well this description. A great deal of social media platforms provides specialized services, such as hiring services in the case of LinkedIn or travel and hospitality services in the case of TripAdvisor, that bring different types of actors together. More often than not, social media work as advertising platforms procuring their revenues through the trading of the attention of their users to advertisers (e.g. 97\% of Facebook revenue in 2017). While recognizing the organizational complexity of social media, this strand of literature nonetheless relegates the role of users in the back seat. The significance of users for platforms seems to be limited to the concepts of externalities or network effects and their perception to such generic roles as producers, consumers, stakeholders or developers [6] [11] [17].

The view of platforms as multisided markets is indicative of the complexity of social media and is usually overlooked by their conception as networking sites. Yet, platforms are more than a specific type of marketplace. Far from being sites of market exchanges alone [15], social media platforms maintain complex data warehousing environments, linked to a series of technologies such as distributed data management systems (e.g. Hadoop), protocols, APIs and social buttons through which data are rendered standardized and portable over platform boundaries and across large portion of the Web [14]. These operations, in turn, require suitable user interface designs to foster specific user participation and a range of data management tools, including personalization systems, AI and machine learning applications [2]. Far from being sites of economic exchange, social media are composite entities whose operations are contingent on the orchestration of these technological capabilities into a dynamic and well-functioning whole. Such an orchestration can be brought to the forefront via the concept of platform design and architecture [48] [49]. Platforms can be viewed as assemblages of different elements that are linked together into adaptable and revisable configurations that render them able to respond to the shifting demands of the broader digital ecosystem into which they are embedded (see e.g. [4] [19] [21] [28]).

The economic and technological complexity of digital platforms indicate that social media are complex organizations made of several types of resources, task structures, roles and positions. It is reasonable to assume that similar to most complex organizations (see e.g. [22] [33] [36] [40]), these attributes and qualities of social media shape the way they operate. Yet, there is no much written on the kind of organizations social media platforms are. There is a growing literature on the adoption of social media technologies by incumbent organizations. However, with the exception perhaps of Wikipedia (see e.g. [1]), social media platforms have not been studied as a particular type of organization. Far from being transaction platforms operating simply as multisided markets or sites of sociality, social media organizations such as Facebook, LinkedIn or TripAdvisor are settings of work, authority and expertise through which a variety of resources are deployed to achieve specific objectives [23].

To sum up, the majority of IS contributions still investigate social media as social networks [5] [26] [34] [38] [44]. The problem with this approach is that it assumes social media to be a kind of neutral conduit of connectivity, glossing over their economic, technological and organizational complexity [15]. On the other hand, the understanding of social media as complex 
economic, technological and organizational entities occasions other problems as it tends to obfuscate the critical role users have historically played as content and data creators rather than simply buyers [23]. In fact, many economists and management scholars do not make a stark difference between such diverse platforms as OpenTable and Facebook or LinkedIn and Google and do not consider the role of user populations other than in the generic and, for that reason, unsatisfactory fashion of value networks (see e.g. [11]).

In this paper, we investigate the transformation of social media platforms by looking at the role different types of users play without sacrificing their economic, technological and economic complexity [24]. We position our research and contribution against the background of the literature reviewed. We build on previous contributions and demonstrate how the innovative capability of social media derives from different forms of user involvement designed to procure specific types of data. The relatively recent introduction of commercial services derived from transaction data signifies a new stage in social media platform evolution that breaks with the practices characteristic of their establishment (networking) and take-off periods (information services). Our research shows how and to what extent these developments are linked to the role of users and the economic relevance of the data created by user platform participation (social data).

\section{Methodology}

We present a longitudinal case study of TripAdvisor which spans from its establishment in 2000 to the end of 2017 [47]. The case study consists of two stages. The first is a pilot study of 7 hotels, 5 restaurants and 3 attractions working with TripAdvisor. The study lasted 4 months ( 3 in Chile, 1 in UK) and was conducted in 2017. The pilot study disclosed the diversity of platform operations and led to the identification of the main types of users, the practices related to the production and exchange of data between hotel owners, main stakeholders and TripAdvisor and to the refinement of research questions. Data were in this phase collected with semi-structured interviews (15), in situ observations and review of various online sources. The second phase is a longitudinal case study of TripAdvisor which is mostly based on online, publicly-available archival records [41] from TripAdvisor media center (https://tripadvisor.mediaroom.com). This online archive comprises files since the early stages of TripAdvisor classified under two categories: "In the News" and "Press releases". The second category entails records of press releases published and maintained on the platform by TripAdvisor itself, providing first-hand, factual information about important matters in the history of the platform. This category is made of 3,388 press releases from 2000 until December 2017, end date of our data collection. 1,677 of these records are in English and they make the primary information source of this case narrative. While varying in size from a few lines to several pages, these records constitute a valuable source of publicly available information for charting the evolution of the platform over time. Data collection was complemented with two secondary interviews of Stephen Kaufer, TripAdvisor CEO over the years ([31] [43]). It is a diffused practice in longitudinal research to use biographies to reconstruct historical evidence [46]. The interviews provided information on the early stages of TripAdvisor and helped us contextualize the data from our online sources.

On a first read, the 1,677 press releases were classified according to their content: roll-outs, partnerships, acquisitions, awards and reports. While we base our report on the entire archive, the roll-outs sub-category (216 publications) has played a crucial role as it provided most of the evidence of the features that have been launched over time which is key to understanding the evolution of the platform. The 216 roll-out press releases were manually analyzed in two consecutive cycles: codes and coding, and pattern codes [35]. Though this analysis allowed us to extract key semantic blocks of the press-releases text, it didn't provide enough of a contextual background on the evolution of TripAdvisor. For this, we relied on a subsection found at the bottom of most of the 1,677 press releases, entitled "About TripAdvisor" that represents the official description of the company by itself, its self-identity, as it were. Changes in this section were tracked manually and resulted in eight initial patterns through which TripAdvisor presents itself. These patterns were eventually reduced to three different stages of TripAdvisor's development: 1) Search engine, 2) Social media platform and 3) End-to-End service ecosystem. The code structure was subsequently superimposed upon the three-stages periodization (search engine, social media, end-to-end service ecosystem) resulting in the mapping of the static nature of the semantic blocks along the temporal axis, as shown in Figure 1.

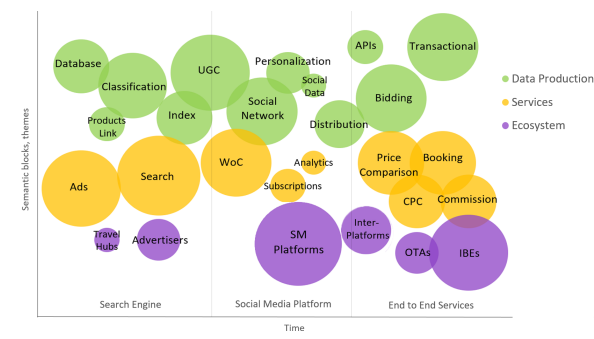

Figure 1: Code Periodization 


\section{Case Study: The patterns of TripAdvisor Evolution}

TripAdvisor is a platform that offers a range of services in the travel sector, most of which have traditionally been associated with user-generated reviews and recommendations. Users participate on the platform by sharing their experiences, providing ratings, and commenting on all kinds of places or tourist attractions around the world. Founded in February 2000 as a travel search engine, TripAdvisor has become one of the world's largest online travel sites that has left an indelible imprint on the travel industry.

Our analysis of the roll-out features and TripAdvisor's own statements indicates three stages in TripAdvisor's evolution. The first stage marks the establishment of TripAdvisor as search travel database and its self-perception as a travel advertising platform (20002005). This is followed by the development of Web 2.0, mobile features and inter-platform connectivity from which the platform still owes much of its public image (from 2006). The third and last stage coincides with the introduction and enhancement of price comparison and booking features and the development of end-to-end services (2013). In what follows, we describe in some detail each of the three stages.

\subsection{Kick-off: Search Engine and Advertising Platform}

Back in February 2000, Stephen Kaufer and his cofounders sought to build a search engine with a travel focus. The first step was to build a travel database with up-to-date content ([31]: 364). Starting with an automated indexing of travel sites didn't have the expected result and the indexing reverted to manual work and was eventually compiled by people who were employed to classify, tag and then write one-line summaries of the travel articles. Although at that time there were many rich travel content sites, it was difficult for users to overcome the fragmentation of online travel information and find what they were looking for. TripAdvisor saw the market opportunity and positioned itself as a search engine built on the in-depth understanding of travel content and user preferences. By relying on its knowledge of site structures and search technologies, TripAdvisor was able to return responses to multi-dimensional queries which most of the travel sites couldn't do as they were still bounded to single destination queries or very limited categories.

In late 2000, a demo website went live to exemplify TripAdvisor's search capabilities, after a year it started to get some traffic. After some initial difficulties, the idea of contextual link advertising emerged as monetiz- ing strategy [31]. Contextual link advertising refers to the display of highly targeted ads selected automatically on the basis of user data (i.e. profile, preferences). In this model, advertising is monetized by a Cost-perClick (CPC) model which means that an advertiser pays a publisher (here TripAdvisor) when the ad is clicked through. Differently from traditional banner advertising, the efficiency of contextual display ads is related to user search data. The more the data the better the chance that relevant ads are displayed and eventually clicked-through. Also, in the CPC model marketers pay for the click-through they perform instead of paying upfront for banner display. This means that TripAdvisor had a margin of improvement in revenue making that was directly proportional to the number of click-through it could generate. To provide contextual ads, TripAdvisor automatically linked a whole client product database with its search database by creating HTML links which contained unique code track ([31] TripAdvisor 4 March 2002). Already "the overall click-through rates on TripAdvisor average $8 \%$, a $32 \mathrm{X}$ improvement over the standard banner response rate of .25\%" (TripAdvisor 3 December 2001). TripAdvisor's click-through rate varied from $4 \%$ to $12 \%$, depending on how relevant the ads offered were.

The other aspect of contextual link advertising is the continuous development of the search capabilities it affords. As part of improving the retrieval of comprehensive travel information about destinations, TripAdvisor launched a dynamic hotel index, a pioneer of its kind, an "up-to-date view of the most popular hotels in a given city" (TripAdvisor 22 November 2002). Interestingly, the definition of this index changed in March 2005. While the previous index measured popularity by using web information, a new algorithm was developed that used "real reviews by real travelers posted on TripAdvisor.com" (TripAdvisor 9 March 2005). This change signaled a turning point in TripAdvisor's evolution as it made user-generated content a milestone of its operations.

\subsection{Social Media Platform and Inter-Platform Connectivity}

Rather than a sudden change from search engine to social media, our data show that TripAdvisor evolved into a social media by gradually attributing importance to user participation as a means for generating content and data. The first mention of user reviews occurred in late 2000 and, even if the first real social media feature (forum) had been launched already in 2004, TripAdvisor described itself as a travel community only in 2006 and as a travel media network in 2007. In December 2007, TripAdvisor launched a new site design, due to the remarkable growth of user participation. User re- 
views and opinions doubled between 2006 and 2007, from five million to 10 million.

Following the enhancement of web 2.0 functionalities, TripAdvisor launched in 2006 Inside which allowed users to utilize wiki functionalities to share their collective knowledge about destinations around the world (TripAdvisor 11 April 2006). The move was in line with bigger changes on the role of users in producing web content, the so called "wisdom of the crowds", and TripAdvisor used it to gain traction as innovator sustained by users. TripAdvisor's Inside featured realtime travel information posted by users and rich content on a variety of topics. A month later TripAdvisor rolled out goLists which allowed users to publish lists of their favorite destinations, attractions, activities, hotels and restaurants (TripAdvisor 8 May 2006). goLists was presented as an innovative way for weighing travel experiences and a useful resource to share and receive insider comments in an organized and searchable format. With goLists, users could vote on the helpfulness and accuracy of each list which resulted in most popular lists being featured more prominently on the site.

"First Social Networking Tool that Combines 20 Million Monthly Visitors, 6 Million Members and 10 Million Travel Reviews and Opinions" headlined TripAdvisor article in the middle of 2007 (TripAdvisor 15 June 2007), referring to a new travel network feature just introduced. The introduction of this feature signaled another milestone in TripAdvisor's evolution toward enriched connectivity. It allowed TripAdvisor users to connect with their networks and share travel information through it, indicating a clear turn toward social networking.

In 2007 TripAdvisor started to gather data not only about destinations but also on user behavior. Seeking to expand and capture relevant content and data, TripAdvisor started to connect with other social media platforms. The platform launched its Local Picks application on Facebook in fall of 2007 and MySpace in spring 2008. This application allowed the easy sharing of food opinions among friends, indicating the best places to eat in any location, from people who have already been there and rapidly became viral. In its aftermath, TripAdvisor grew its restaurant offering from less than 100,000 establishments to nearly 500,000 in approximately 15 months (TripAdvisor 10 February 2009). Cities I've Visited and Traveler IQ Challenge were applications rolled out on Facebook in June 2007 and in MySpace on May 2008. As for all MySpace (and Facebook) apps, TripAdvisor apps on this platform were able to access public profile information available including users' friend lists, interests, photos $\&$ albums, video, as well as status \& mood (TripAdvisor 14 May 2008).
In the following years, TripAdvisor continued strengthening its connectivity with other platforms and expanding its user services. In 2009, thanks to the partnership with OpenTable and Toptable - leading providers of online restaurant reservations for diners TripAdvisor's users were able to make restaurant reservations in the US or UK. TripAdvisor also offered dynamic maps, using Google maps to show where restaurants are located and, taking advantage of the mobile geolocation capabilities, helped users find the best restaurants, as rated by locals. In 2013 the partnership with Viator - the leading resource for researching and booking tours and activities worldwide - gave TripAdvisor's users the opportunity to find and book tour activities. By clicking "Book Now" button, users could directly access Viator.co and its wide selection of tours and activities in popular destinations around the world. The partnership with Facebook grew stronger with two new apps: Trip Friends in 2010 and Friend of a Friend in 2012. Similar to the Traveler Network feature, Trip Friends displayed a list of friends who had already been to the location a user was searching for. Friend of a Friend in TripAdvisor's words represented "the next step in making travel planning more social for the TripAdvisor global community" (TripAdvisor 11 April 2012). In addition to Facebook's friends, Friend of a Friend allowed sharing to friends of each friend thus expanding a user's network. The features effectively personalized user search results displaying first the reviews of Facebook's friends (followed by reviews of Facebook's friends of friends). In a move toward a more personalized offering, in late 2014 TripAdvisor launched Just for You feature which sorted hotels based on a user's individual preferences and search history on the platform. Upon searching hotels for a specific destination, users saw a variety of tags allowing them to select their travel preferences, such as travel style, location, price range, hotel class, amenities and brand. Through the new Just for You feature, TripAdvisor incorporated this feedback along with a user's prior search and contributions on the site to deliver more personalized hotel results.

In October 2012, TripAdvisor announced a new app that gave business owners (hoteliers) an uncomplicated way to enrich their Facebook Pages with TripAdvisor content. This app was designed to help businesses attract more guests by using TripAdvisor traveler feedback and is an expansion of the popular TripAdvisor widgets. Using this widget, businesses were able to create a TripAdvisor tab on their Facebook Page which included their ratings, recent reviews, awards, photos and ranking on the site.

\subsection{End-to-End Service Ecosystem}


In 2013, the all-in-one Hotel Price Comparison search went live (TripAdvisor 5 June 2013). This new feature marked a watershed in the way hotel profiles were produced, being the first to match real-time pricing and availability with TripAdvisor's reviews and opinions in a simple layout. The feature obtained the price and availability from multiple booking partners (Online Travel Agencies and Internet Booking Engines) and displayed them in one view. When users picked the dates of stay, TripAdvisor displayed a list of available hotels with their average prices for this stay. This way, users can search and compare hotel prices at a glance, without having to leave the platform. Users can easily select and book their hotel by clicking through to the booking partners' sites to complete the transaction.

By 2014 TripAdvisor started to introduce a range of end-to-end services whereby users could get through the entire travel consumption process, from search destination to actual hotel reservation, without leaving the platform. Simplifying the hotel booking process, TripAdvisor first rolled out Instant Booking for mobile devices in June 2014 and extended it to all devices in the US and UK by September 2015 (TripAdvisor 11 June 2014; 14 September 2015). This feature streamlined the booking process which could be completed without opening a new window on the booking partners' sites to complete the transaction.

Instant Reservation arrived in September 2014, leveraged by the acquisition of Lafourchette (TripAdvisor 18 September 2014). Instant Reservation expanded the functionality of Instant Booking to restaurants, allowing users to complete their reservations without leaving the site. Instant Reservation was available on mobile and desktop. On November, also the Attraction section exhibited an Instant Feature by integrating tour inventory display and pricing data from Viator, a leading tour agency, which had been acquired by TripAdvisor in August (TripAdvisor 13 November 2014). When users visit an Attraction page on the platform, they are presented with up to three tour options, such as small group, private or skip-the-line options, along with descriptions and prices for each. An instant booking functionality complements the offering.

In 2014, as part of the inter-platform connectivity expansion, TripAdvisor announced a new feature for mobile called Ride there with Uber. This allowed users to easily reserve a ride with Uber to restaurants, attractions and hotels. TripAdvisor was one of the first to integrate Uber functionality into its platform by using Uber APIs. When users searched for restaurants, attractions and hotels on TripAdvisor they are presented with an estimate of Uber car fares and the wait times for pickup. Clicking Ride there with Uber button allowed redirecting to Uber thus completing the reserva- tion and having a car sent to the user location (TripAdvisor 20 August 2014).

In a similar move, TripAdvisor teamed up with Deliveroo enabling its users the access to Deliveroo's restaurant network. The scheme connected more than 20,000 restaurants across 12 countries throughout Europe, the Middle East and the Asia Pacific regions. Restaurants listed in both TripAdvisor and Deliveroo are displayed a button order online. By clicking it, TripAdvisor visitors are redirected to the specific restaurant on the Deliveroo app to complete their orders.

Adopting trendy technology and strengthening the integration with Facebook, TripAdvisor rolled out its chatbot on Facebook Messenger in early 2017. Chatbots are simple artificial intelligence computer systems that you can chat with via text. TripAdvisor can receive user requests via Facebook Messenger asking for travel advice and recommendations regarding popular restaurants, attractions, hotels, and flights. TripAdvisor then searches all over its database to instantly deliver the best response to the message. For example, if a user is in New York City and craves sushi s/he can login into Facebook Messenger and send a message to TripAdvisor asking for sushi restaurants nearby his/her current location. TripAdvisor's chatbot can be used as a "social" tool as users can invite anyone to the chatroom, sharing options and "likes", in so doing sharing decisions and plans. TripAdvisor's bot learns about users' preferences improving its responses as users use it.

\section{Discussion}

Our report of TripAdvisor reveals a complex and dynamic business ecosystem in which TripAdvisor itself, users and a range of other businesses and platforms are linked together by various data and revenue flows. These links and the data and revenues flows they generate rest, in turn, on an elaborate technological infrastructure that brings a large ecosystem of actors together and orchestrates the ubiquitous presence of users across a large spectrum of platform (TripAdvisor) and inter-platform (TripAdvisor, Facebook, booking partners) operations. The content and data supplied by users directly (reviews, ratings) or indirectly (click patterns and user interactions) are no doubt what grants TripAdvisor its distinctive and widely recognizable status as a platform and the means through which the platform qualifies the services it produces and trades in the market [13] [14].

Our empirical narrative shows that the involvement of different groups of users has been shifting throughout the history of the platform along with the types of actions and the data such actions generate. The period- 
ization scheme (search engine, social media platform, data services ecosystem) we derived from the reconstruction of TripAdvisor's evolution allows dissecting the variable forms of user involvement around which the platform has spun, and continues to spin, its business operations [10].

Table 1 below offers an analytic view of the operations of TripAdvisor we derive from the empirical narrative of the platform. The vertical axis of the table summarizes i) the different types of data generated and used by the platform, ii) the core functionalities the platform has implemented over time and iii) the main partners it has relied upon, together with the strategy it has adopted in relation to its ecosystem's partners. These are mapped onto the horizontal axis along the three distinct platform stages (Search Engine, Social Media, Data Service Ecosystem). It is important to note that the evolution of TripAdvisor is cumulative or path dependent. Each stage is built on the data and functionalities produced in the preceding stage and enabled by its own specific data types and platform functionalities.

\begin{tabular}{|c|c|c|c|}
\hline \multicolumn{4}{|c|}{ Table 1: The Evolution of TripAdvisor } \\
\hline & $\begin{array}{l}\text { Search En- } \\
\text { gine }\end{array}$ & Social Media & $\begin{array}{l}\text { Data Service } \\
\text { Ecosystem }\end{array}$ \\
\hline $\begin{array}{l}\text { Data } \\
\text { Types }\end{array}$ & $\begin{array}{l}\text { Hotel data } \\
\text { Destination } \\
\text { data (both } \\
\text { imported from } \\
\text { hotel websites } \\
\text { and the Web) } \\
\text { Product data } \\
\text { (HTML links) }\end{array}$ & $\begin{array}{l}\text { Social data } \\
\text { (actions and } \\
\text { opinions by } \\
\text { user platform } \\
\text { participation } \\
\text { Network data } \\
\text { (friends' and } \\
\text { friends of } \\
\text { friends' data } \\
\text { from social } \\
\text { media plat- } \\
\text { forms) } \\
\text { User Generated } \\
\text { Content (re- } \\
\text { views, forum, } \\
\text { Q\&A) }\end{array}$ & $\begin{array}{l}\text { Real-time } \\
\text { transaction } \\
\text { data (Booking } \\
\text { generated by } \\
\text { users and } \\
\text { Bidding gener- } \\
\text { ated by hotels } \\
\text { and OTAs) }\end{array}$ \\
\hline $\begin{array}{l}\text { Platform } \\
\text { Function- } \\
\text { alities }\end{array}$ & $\begin{array}{l}\text { Indexing and } \\
\text { Classifying } \\
\text { Searching } \\
\text { (multi query) }\end{array}$ & $\begin{array}{l}\text { Networking } \\
\text { Producing \& } \\
\text { Consuming } \\
\text { content (wikis, } \\
\text { rating, review- } \\
\text { ing) } \\
\text { Personalizing } \\
\text { results (filtering, } \\
\text { selecting) } \\
\text { Subscribing }\end{array}$ & $\begin{array}{l}\text { Comparing } \\
\text { (price and } \\
\text { content) } \\
\text { Booking } \\
\text { Bidding }\end{array}$ \\
\hline $\begin{array}{l}\text { Ecosystem } \\
\text { partners } \\
\text { and Strat- } \\
\text { egy }\end{array}$ & $\begin{array}{l}\text { Advertisers } \\
\text { (OTAs and big } \\
\text { hotel chains } \\
\text { and travel } \\
\text { sites at the } \\
\text { beginning) } \\
\text { Media model }\end{array}$ & $\begin{array}{l}\text { Social media } \\
\text { platforms } \\
\text { App develop- } \\
\text { ment and de- } \\
\text { centralization }\end{array}$ & $\begin{array}{l}\text { OTAs } \\
\text { IBEs } \\
\text { Sharing econ- } \\
\text { omy platforms } \\
\text { App acquisi- } \\
\text { tion, integra- } \\
\text { tion of services } \\
\text { and recentrali- } \\
\text { zation }\end{array}$ \\
\hline
\end{tabular}

In the introduction we asked how the distinct status of social media as business actors has evolved and the degree to which their operations continue to be dependent on (end) users as content and data generators. In particular, we asked (a) what role would social data play in the expansion of social media to the provision of service belonging to more traditional sectors? (b) what kind of ecosystems emerge as social media diversify their operations? We found out that the three stages in TripAdvisor's evolution are conditioned by the platform functionalities implemented in each stage and the data types produced and exchanged among different groups of users. Platform operations are, in turn, conditioned by the dynamic forms of user involvement the platform designs and their interdependencies. Forms of user involvement often work in tandem with specific platform functionalities to establish complex user model configurations that are eventually reinforced by the overall platform strategy. Our findings clearly indicate that each phase of the platform evolution is characterized by specific models of users that alternately represent the main resources and the main clients of the platform. In line with the literature on multisided platforms the evolution of TripAdvisor can be thought as the modification or addition of new user model configurations. Differently from this literature, however, our contribution points to the fact that new user model configurations are always built on dataresources. Such resources are assembled gradually as the platform evolves and diversifies its operations (i.e. search-engine, social media, service ecosystem).

In the first stage of the platform (approximately 2000-2005) end-users were modeled just as atomized information seekers (there was no interaction between users) and the platform functionality and design were accordingly geared to accommodate a search-oriented platform, profiting from the patterns of clicks (data) associated with this through a CPC advertising model [45]. The data-resources the platform was able to produce from the operations of indexing and classifying web content on hotels and destinations empowered the searching functionality on the platform which in turn generated user engagement and user platform participation and data on user preferences (social data).

The social data and search capabilities cumulated in the first phase became integrated in a much more comprehensive redesign which sought to accommodate additional forms of user involvement, most notably user generated content and various forms of user interaction [2] [3] [14] [20] during the second stage of the platform evolution (roughly 2006-2013). Most of the TripAdvisor social media features rolled out, one after the other, in this period (such as Inside, goLists, Travel Network, Cities I've Visited). This, together with the links of TripAdvisor to other social media sites (e.g. 
Facebook, MySpace) through apps and widgets caused a complete redesign of the model of users and the concomitant redefinition of TripAdvisor to a social media platform able to grow on the basis of data and content procured by user platform participation. The usertraveler which was the main client of the searching functionality became instead the main source of data for the platform, generating different types of data (e.g. reviews and ratings) on the basis of which the platform is able to provide a set of new algorithmically driven functionalities [16] [39].

Taken together, these changes reconfigured the functional identity of the platform and made TripAdvisor an independent source of data production. Significantly, the producers of data-resources in the second stage are not employees anymore but end-users (travelers) contributing content and data. Because of the new user generated data-resources the platform has been able to provide personalized services to users. The production of destination profiles, e.g. places and hotels can be personalized through the aggregation of user ratings and other forms of crunching user data [2]. The searching functionality was empowered by popularity and other measures that could be computed on the basis of user involvement. Destination profiles became a very complex algorithmic inter-platform arrangement (Popularity Index, Top Value, Just for You) very different from the manual processing of travel information by TripAdvisor staff, characteristic of the search engine stage. The development of social networking tools and inter-platform connectivity meant that data-resources and the data services produced, such as personalized destination profiles, started to be displayed not only on TripAdvisor but also on other social media partners. These changes also enabled the development of several other services such as dining reservation, flight booking and vacation rentals, all linked, in one way or another, to user generated content and user interaction within the platform and across platforms.

Taken together these new features and dataresources brought the transition to the third stage and the transformation of TripAdvisor from social media to all-in-one-place destination for travelers or data services ecosystem. Our empirical narrative demonstrates the increased complexity of the operations and related services which TripAdvisor is currently able to offer to a range of users, with end-users being just one group among many others. The platform operations have increased both in variety (searching, comparing, booking, reviewing) and in scope or kind (hotels, restaurants, food delivery, tours and so on). At the same time, the data services ecosystem we describe as the last stage in the evolution of TripAdvisor seems to extend the existing organizational modalities of the plat- form (its data-resources, data-services and operations) to more traditional types of services.

The provision of hotel booking services via the platform implies that user data, preferences and personalized recommendations are now used to disrupt extant hotel booking services. TripAdvisor has contributed to developing a new business ecosystem, which has grown adjacent to the existing one, adding both new users, new partners and new operations. Internet Booking Engines (IBEs) currently play a fundamental role in transmitting data about room availability and price and, in the case of Instant booking, also do the booking. Currently, there are 325 certified IBEs via which hotel owners can advertise their rooms directly on TripAdvisor. These developments point to a complex system of business relations and transactions that are taking place underneath the user interface, through mostly an automated and real-time system of data exchanges and platform functionalities. The emergence of new users and new operations bring changes for existing users and existing operations. Travelers continue to have a predominant role as they remain key data and content providers but they, in addition, obtain the status of buyers through the final act of room booking. Hoteliers become clients as they are provided with more platform functionalities and data analytics services. Also, hoteliers can now directly bid for user clicks alongside OTAs to see their offers displayed in price comparison tabs and they can also offer direct booking on TripAdvisor through their connectivity partners (i.e. IBEs). The introduction of booking services that provide revenues through commission breaks away from the media-based advertisement model TripAdvisor has used during the first and second stage of its evolution and from its dependency on OTAs and big hotel chains which have been TripAdvisor's major clients. The booking model introduces a new class of intermediaries (connectivity partners) which provide the infrastructure of data and technologies that single hoteliers (even the majority of hotel chains) seldom have.

In the third and current phase of its evolution, TripAdvisor acquires the status of a hub of a complex data-service ecosystem. Its central position derives from its capability, built over the years, of producing multiple data formats and multiple user models to differentiate and expand the scope of its data services.

\section{Conclusions}

We have reconstructed the evolutionary pattern of TripAdvisor with the view of addressing to what extent the operations of social media as business actors continue to be dependent on (end) users as content and data generators [10]. Building on prior research in the 
field [26] [38] [39], our study indicates the crucial role the modeling of user and the data derived from their interaction play in sustaining the operations of TripAdvisor. Indeed, platforms evolve by adding and orchestrating different user-sides [6] [12] [17]. Complementing existing literature on platform growth and evolution, our analysis unravels the multiple roles different users perform, how the shifting nature of these roles is linked to the production of data-resources and the implementation of platform functionalities and, critically, the ways these roles change and support one another leading to the establishment of what we refer to as data service ecosystem. These findings suggest that the evolution of social media is linked to the production, exchange and use of different types of data and the ways such data are drawn upon to support the services social media platforms offer to increasingly complex configurations of user-types. Critical to these configurations is the dynamism and flexibility by which user involvement continuously shifts from production (social data and user-generated content) to consumption of these services, an alternation that takes place along several and rather different trajectories.

The shifting and interdependent roles users perform and the data services derived from these roles are linked to the transformation of TripAdvisor to a data services ecosystem and constitutes the key contribution our paper makes to the literature. Social media platforms such as TripAdvisor cannot be framed as community or user networks alone as this comes at the expense of other central characteristics that shape the functional identity and business behavior of the platform. The links users maintain with one another are heavily mediated by the functional identity of the platform as well as by the types of platform participation and user interaction the platform affords. Crucially, the different affordances of the platform as well as the entire technological infrastructure that sustains them are linked to the roles of users as data producers and service consumers which evolve overtime in complex and often unpredictable ways [2] [14] [20].

The current changes undergone by TripAdvisor could be linked to the platform strategy to integrate the fragmented travel and entertainment value chain and recentralize data flows and exchanges within its platform and ecosystem boundaries [12] [14]. TripAdvisor is in the position to exploit the power of its large user base by offering new data services. It can do so because it has taken the data produced by user interactions, reviews and ratings into entirely new regions. Other social media platforms such as Facebook or LinkedIn show an analogous pattern toward the development of new services empowered by a growth and expansion of their data-resources which are linked to a constant redesign of user-models and addition of user- types. This, together with the increased automation that the complexity of these exchanges requires seems to point to a broader evolutionary path along which social media platforms and the digital economy are developing.

\section{References}

[1] Aaltonen, A., and Lanzara, G. F. "Building Governance Capability in Online Social Production: Insights from Wikipedia". Organization Studies, 36(12), 2015, pp. 1649-1673.

[2] Alaimo, C., and Kallinikos, J. "Computing the Everyday: Social Media as Data Platforms". The Information Society, 33(4), 2017, pp. 175-191.

[3] Alaimo, C., and Kallinikos, J. "Encoding the Everyday: The Infrastructural Apparatus of Social Data". In Big data is not a monolith: Policies, practices, and problems, ed. C. Sugimoto, H. Ekbia, and M. Mattioli, 2016, pp. 77-90. Cambridge MA: MIT Press.

[4] Baldwin, C. Y., and Woodard, C. J. "The Architecture of Platforms: A Unified View," in Platforms, Markets and Innovation, A. Gawer (ed.). 2009, pp. 19-44. Edward Elgar, Cheltenham.

[5] Berger, K., Klier, J., Klier, M., and Probst, F. "A Review of Information Systems Research on Online Social Networks". Communications of the Association for Information Systems, 35(1), 2014, pp. 145-172.

[6] Boudreau, K. "Open Platform Strategies and Innovation: Granting Access vs. Devolving Control". Management Science, 56(10), 2010, pp. 1849-1872.

[7] boyd, d. and Ellison, N. "Social Network Sites: Definition, History, and Scholarship". Journal of ComputerMediated Communication, 13, 2008, pp. 210-230.

[8] Burgess, J., Marwick, A. and Poell, T. eds., The Sage Handbook of Social Media. SAGE, 2018.

[9] Cetto, A., Klier, M., Richter, A. and Zolitschka, J.F., ““'Thanks for Sharing”- Identifying Users' Roles Based on Knowledge Contribution in Enterprise Social Networks". Computer Networks, 135, 2018, pp. 275-288.

[10] de Reuver, M., Sørensen, C. and Basole, R.C., "The Digital Platform: a Research Agenda". Journal of Information Technology, 2017, pp. 1-12.

[11] Evans, D.S. and Schmalensee, R., The Industrial Organization of Markets with Two-Sided Platforms (No. w11603). National Bureau of Economic Research. 2005.

[12] Gawer, A. Platforms, Markets and Innovation. Edward Elgar Publishing, Cheltenham, 2009.

[13] Gawer, A. and Cusumano, M.A., "Industry platforms and ecosystem innovation". Journal of Product Innovation Management, 31(3), 2014, pp. 417-433.

[14] Gerlitz, C. and Helmond, A. "The Like Economy: Social Buttons and The Data-Intensive Web". New Media and Society 15 (8), 2013, pp. 1-18.

[15] Gillespie, T. "The Politics of "Platforms"”. New Media and Society, 12(3), 2010, pp. 347-364.

[16] Gillespie, T. "The relevance of algorithms". In Media Technologies: Essays on Communication, Materiality, and Society, ed. T. Gillespie, P. J. Boczkowski and K. 
A. Foot. 2014, pp. 167-194. Cambridge, MA: MIT Press.

[17] Hagiu, A. and Wright, J., "Multi-Sided Platforms". International Journal of Industrial Organization, 43, 2015, pp.162-174.

[18] Hanseth, O. "The economics of standards". In From control to drift: The dynamics of corporate information infrastructures, ed. C. Ciborra, 2000, pp. 56-70. Oxford, UK: Oxford University Press.

[19] Hanseth, O., and Lyytinen, K. "Design Theory for Dynamic Complexity in Information Infrastructures: The Case of Building Internet". Journal of Information Technology (25:1), 2010, pp. 1-19.

[20] Helmond, A. "The Platformization of the Web: Making Web Data Platform Ready". Social Media+ Society, 1(2), 2015, pp. 1-11.

[21] Henfridsson, O., and Bygstad, B. "The Generative Mechanisms of Digital Infrastructure Evolution". MIS Quarterly, 37(3), 2013, pp. 907-931.

[22] Kallinikos, J. "Computer-based technology and the constitution of work: A study on the cognitive foundations of work", Accounting, Management and Information Technologies, 9(4), 1999, pp. 261-291.

[23] Kallinikos, J. and Constantiou, I. "Big data revisited: a rejoinder", Journal of Information Technology, 30(1), 2015, pp. 70-74.

[24] Kallinikos, J., Hasselbladh, H. and Marton, A. "Governing social practice: Technology and institutional change", Theory and Society, 42(4), 2013, pp. 395-421.

[25] Kane, G. C., Alavi, M., Labianca, G., and Borgatti, S. P. "What's Different About Social Media Networks? A Framework and Research Agenda", MIS Quarterly 38 (1), 2014, pp. 275-304.

[26] Kane, G. C. and Ransbotham, S. "Research NoteContent and Collaboration: An Affiliation Network Approach to Information Quality in Online Peer Production Communities". Information Systems Research, 27(2), 2016, pp. 424-439.

[27] Kaplan, A. M., and Haenlein, M. "Users of The World, Unite! The Challenges and Opportunities of Social Media". Business Horizons, 53, 2010, pp. 59-68.

[28] Kazan, E., Tan, C.W., Lim, E.T.K., Sørensen, C., Damsgaard, J., "Disentangling Digital Platform Competition: The Case of UK Mobile Payment Platforms". Journal of Management Information Systems, 35. 2018, pp. 180-219.

[29] Leonardi, P. M. "Social Media, Knowledge Sharing, and Innovation: Toward a Theory of Communication Visibility", Information Systems Research (25:4), 2014, pp. 796-816.

[30] Leonardi, P.M., Huysman, M. and Steinfield, C., "Enterprise Social Media: Definition, History, and Prospects for the Study of Social Technologies in Organizations". Journal of Computer-Mediated Communication, 19(1), 2013, pp.1-19.
[31] Livingston, J. Founders at work: Stories of startups' early days, Berkeley, Calif: Apress. 2007.

[32] Majchrzak, A., Faraj, S., Kane, G.C. and Azad, B., "The Contradictory Influence of Social Media Affordances on Online Communal Knowledge Sharing”. Journal of Computer-Mediated Communication, 19(1), 2013, pp. 38-55.

[33] March, J.G., Primer on Decision Making: How Decisions Happen. Simon and Schuster. 1994.

[34] McKenna, B., Myers, M.D. and Newman, M., "Social Media in Qualitative Research: Challenges and Recommendations", Information and Organization, 27(2), 2017, pp. 87-99.

[35] Miles, M. B., Huberman, A. M. and Saldaña, J. Qualitative Data Analysis: A Methods Sourcebook, California: SAGE. 2014.

[36] Mintzberg, H., The Structuring of Organizations: A Synthesis of The Research. New Jersey. 1979.

[37] Morville, P. Ambient findability. CA: Sebastopol. 2005.

[38] Oestreicher-Singer, G., and Zalmanson, L. "Content or Community? A Digital Business Strategy for Content Providers in the Social Age," MIS Quarterly (37:2), 2013, pp. 591-616.

[39] Orlikowski, W. and Scott, S. V. "The Algorithm and the Crowd: Considering the Materiality of Service Innovation", MIS Quarterly, (39: 1), 2015, pp. 201-216.

[40] Perrow, C., Complex Organizations: A Critical Essay. New York: McGrawHill. 1986.

[41] Rogers, R. Digital methods. Cambridge, Massachusetts: The MIT Press. 2013.

[42] Rosenfeld, L. and Morville, P., Information Architecture for the World Wide Web. O'Reilly Media. 2002.

[43] Schaal, D. "The Definitive Oral History of Online Travel" Skift (available at https://skift.com/history-of-onlinetravel/; retrieved September 10, 2017). 2016.

[44] Susarla, A., Oh, J.H. and Tan, Y., "Social Networks and The Diffusion of User-Generated Content: Evidence from Youtube". Information Systems Research, 23(1), 2012, pp. 23-41.

[45] Turow, J., The Daily You: How the New Advertising Industry Is Defining Your Identity and Your Worth. Yale University Press. 2012.

[46] Weick, K.E., "The Collapse of Sensemaking in Organizations: The Mann Gulch Disaster". Administrative Science Quarterly, 1993, pp. 628-652.

[47] Yin, R. K. Case Study Research: Design and Methods. London, UK: Sage. 2009.

[48] Yoo, Y., Henfridsson, O., and Lyytinen, K. "Research Commentary-the New Organizing Logic of Digital Innovation: An Agenda for Information Systems Research", Information Systems Research (21:4), 2010, pp. 724-735.

[49] Zittrain, J. L. The Future of the Internet and How to Stop It. New Haven: Yale University Press. 2008 